\title{
Nursing Work Team Effectiveness and Organizational Commitment among Intensive Care Units Staff Nurses: The Pathway for Enhancement Zohor Zakaria ${ }^{1}$, Rehab AbouShaheen ${ }^{2}$ \\ ${ }^{1,2}$ Lecturer of nursing administration, Faculty of Nursing, Tanta University
}

\section{Abstract}

Background: Nursing teamwork effectiveness is a vital aspect of the functioning of any hospital and a basic structural component of hospitals' design. Effective nursing teamwork can be predicted as one of the effectively adopted of the health services and associated with organizational commitment. Aim of the study: Determine the relation between nursing work team effectiveness and organizational commitment among intensive care units staff nurses. Subjects and Method: Research design: A descriptive correlational research design was utilized in this study. Setting: Tanta University Main Hospital in all intensive care units. Subjects: A convenience sample including all staff nurses no (332) working in previous setting. Tools of data collection: Two tools were used. Tool I: Nursing Work Team Effectiveness Structured Questionnaire that included two parts. Part 1 concerned with socio demographic data, part2 included eight dimensions of team effectiveness. Tool II: Organizational Commitment Scale that used to assess staff nurses organizational commitment. Results: Slightly less than half $45.36 \%$ of staff nurses have moderate level of total team effectiveness. More than half $62.58 \%$ of staff nurses had moderate level of organizational commitment. There is positive significant correlation between total team effectiveness and total organizational commitment between staff nurses $\mathrm{p}<0.001$. Conclusion:Staff nurses had moderate level of work team effectiveness and also organizational commitment. Nursing teamwork effectiveness has a positive influence on organizational commitment. Recommendation: Adjust hospital policies to focus hospital systems and structures on team-based rather than hierarchical. Creating continuous assessment and evaluation of team effectiveness to determine which dimensions of team effectiveness need to be improved.

KeyWords: ICU Staff nurses, Nursing team effectiveness, Organizational commitment, pathway for enhancement. 


\section{Introduction}

Nursing teamwork effectiveness is one of the most important fields, since it is recognized that more nurses effective teams lead to higher team performances, innovativeness, and sustainability ${ }^{(1)}$. The need for effective nursing teamwork has been emphasized as being necessary for improving care quality. Increasing the complexity of healthcare systems, ineffective teamwork has been recognized as a major factor contributing to decreased patient outcome and it is important predictor for missed nursing care, thus effective teamwork worldwide is crucial for enhancing nurses' productivity, efficiency, creativity and performance ${ }^{(2,3)}$. Teams provide diversity in knowledge, attitudes, skills and involvement, whose integration makes it possible to supplyrapid, flexible and innovative responses to problems, challenges, and improving the satisfaction of staff nurse work team ${ }^{(4)}$.

The success of organizations and the overall production of nurses' knowledge depend to a large extent on the effectiveness of teams ${ }^{(5)}$. Nursing team, defined as the registered nurses, licensed practical nurses and nursing assistants who work together on a patient care unit to provide nursing care to a group of inpatients ${ }^{(6,7)}$. To achieve team effectiveness in any organization, we must focus on; purpose and goals, roles, team processes, team relationships, intergroup relations, problem solving, passion and commitment, and skills and learning ${ }^{(8)}$. Effective nursing teams work need clear roles, clear purpose, standards and goals and also a shared understanding of the desired purpose. Nursing team members should have sense of responsibility and creativity for high performance ${ }^{(9)}$. Specific knowledge and skills about how to work as effective team are needed. Nursing team should be able to develop their skills and it is important to monitor progress at the individual and also the team level. Team meetings should be productive. Decisionmaking and problem solving are a critical aspect for nursing team working. Team members need access to the required data in order that they will make the proper decisions. Communication should be open, clear and teamwork should be based on positive relations and cohesiveness ${ }^{(10,11)}$.

There is a strong belief that effectiveness of nurses' teams received top priority within diverse healthcare setting especially in intensive care unit ${ }^{(12)}$.The intensive care unit (ICU) is a specialized hospital unit dedicated to the care of patients requiring life-support and those at extremely high 
risk for organ failure and death ${ }^{(13)}$. ICU nurses are responsible for closely monitoring and reporting changes in patients' health and wellbeing. Unlike other members of the ICU team who care for all patients at any given time. nurses are prevailing members of the ICU team because they're directly involved in most ICU treatments, they're responsible for assessing vital signs, delivering drugs, and monitoring for complications of therapy Basically, the team is the body of coordinated and consistent performance that combines completion of the mission's objectives, and interrelated ideas, actions and emotions. Teamwork can be expected to positively affect the organizational performance and increasing nurses' commitment to the organization ${ }^{(14,15)}$.

Organizations require commitment to survive and to realize the objectives. Nurses with high organizational commitment expose higher performance and achieving the organization's objectives (16). Organizational commitment defined as an individual's identification with and involvement in a specific organization. ${ }^{(17)}$. Organizational commitment can be summarized as a desire to stay a member of the organization, willingness to demonstrate a high performance within the organization, and confidence in the organization's goals and values ${ }^{(16)}$.
Committed nurses are internally motivated. Their intrinsic rewards come from the acts and positive outcomes instead of the conditions that are controlled by others. Organizational commitment increases the nurses' performance, job satisfaction, and organizational productivity and decreases rate of staff turnover and absenteeism. Similar to this, personal characteristics, roles and job characteristics, structural characteristics, work experience, and status of the working environment are expressed as factors affecting the degree of organizational commitment ${ }^{(14)}$.The organization commitment includes three essential domains, namely affective, continuance and normative commitment. Firstdomain affective commitment which know as emotional attachment to an organization; second, continuance commitment reflects the perceived costsbenefit evaluation of maintaining organizational membership; third, normative commitment reflects the feelings of obligation to remain with the organization $^{(18,19)}$

\section{Significance of study}

Nursing profession is a vital pillar of society, and healthcare delivery relies heavily on nursing staff ${ }^{(20)}$. Challenges among nurses internationally are several such as suffering from absenteeism, high turnover rate with low organizational 
commitment $^{(18)}$. So it is imperative to find path way for enhancement the nurses' commitment to their work to enhance the organization as a whole especially in ICU where it requires specialized nursing care, high levels of attention and responsibility to provide effective care for critically ill patients who admitted to it.

Many studies have been made in recent years by scholars, management consultants about the positive benefits of effective work teams for organizations. Better understanding for team effectiveness is a path way for team management and enhancement ${ }^{(2)}$.More specifically, teams are said to contribute to better outcomes for organizations due to enhance performance, productivity and commitment to the organization ${ }^{(14)}$. Therefor this study aimed to determine the relationship between staff nurses' work team effectiveness and organizational commitment in ICU at Tanta Main University Hospitals.

\section{Aim of the study}

Determine the relation between nursing work team effectiveness and organizational commitment among intensive care units staff nurses.

\section{Research questions}

1- What is the level of nursing work team effectiveness?
2- What is the level of staff nurses organizational commitment?

3- Is there relation between nursing work team effectiveness and their organizational commitment?

\section{Subjects and Method}

\section{Study design}

Descriptive correlational study design was used in the present research. It is a design that uses questionnaire to detect variables and relationship among them when enough information occurs. This type of study allowed variables to be examined in a situation that has already occurred, and no attempt was made to control or manipulate the situation ${ }^{(21)}$.

\section{Setting}

The study was conducted at Tanta University Main Hospital at Gharbia Governorate, Egypt in six intensive care units which included Neurological, Medical, Chest, Psychiatric, Neonatal and Cardiology intensive care units.

\section{Subjects}

A sample of convenience including all staff nurses $n=(332)$ working in previous settings and available at time of data collection.

\section{Tools of data collection}

Twotools wereutilizes to collect the study data 


\section{Tool I: Nursing Team Work} Effectiveness Questionnaire. It was developed by Lurie, et al. (2011) ${ }^{(22)}$ and modified by the researchers to assess staff nurses team effectiveness. It included two parts:

Part 1: Nurses personal data as age, gender, marital status, unit name, job, qualification and years of experience.

Part 2: It consists of (56) items which divided into eight dimensions as follows;

- Purpose and goals (seven items)

- Roles(seven items)

- Team processes (seven items)

- Team relationships (seven items)

- Intergroup relations(seven items)

- Problem solving (seven items)

- Passion and commitment (seven items)

- Skills and learning(seven items)

\section{Scoring system}

Nurses'response was scored on 5 point Likert Scale. It ranged from 1= strongly disagree, 2=disagree, $3=$ neutral,4=agree, $5=$ strongly agree. The total score calculated by cutoff point and summing scores of all categories. The total scores represent varying levels as follows:

- High level of team effectiveness $>75 \%$

- Moderate level team effectiveness 60$75 \%$

- Low level team effectiveness $<60 \%$

\section{Tool II: Organizational Commitment Scale}

This tool is modified by the researchers guided by Meyer and Allen (1997) ${ }^{(23)}$. It was used to assess staff nurses' organizational commitment. It consisted of (18) items which divided into three dimensions as follows:

- Affective commitment(six items)

- Continuance commitment(six items)

- Normative commitment(six items)

\section{Scoring system}

Nurses' responses were measured on a five point Likert scale ranging from 1=strongly disagree, 2=disagree, 3=neutral, 4=agree, $5=$ strongly agree. The total score was calculated by cutoff point and summing scores of all categories. The total score represent varying levels of nurses' organizational commitment as follows:

- High level of nurses' organizational commitment $<75 \%$

- Moderate level of nurses' organizational commitment from $60 \%$ to $75 \%$

- Low level of nurses' organizational commitment $>60 \%$.

\section{Method}

\section{Tools Validity}

Study tools contents were developed and tested for its validity by jury of 5 academic 
staff in nursing administration at different Faculties of Nursing. The validity of the tools aimed to judge its clarity, comprehensiveness, relevance and accuracy. All of their comments were taken into consideration; some items were re-phrased.

\section{Tools Reliability}

The Cronbach's Alpha test was used for study tools reliability. The calculated reliability was

- $\quad(\mathrm{r}=0.982)$ for Nursing Team Work Effectiveness Questionnaire

$-(\mathrm{r} \quad=0.901 \quad)$ Organizational Commitment Scale

\section{Approval}

An official permission was obtained from the hospital authorities in the identified setting to collect the necessary data.

\section{Pilot Study}

A pilot study was carried out after the experts' opinion and before starting the actual data collection. It was carried out on a sample $10 \%$ of staff nurses (30) and they excluded from the main study sample during the actual collection of data. The aim of pilot study was to test the sequence of items, clarity, applicability, and relevance of the questions. Necessary modifications were done. Pilot study also served to estimate the time required for filling the questionnaire sheets

\section{Ethical Considerations}

Purpose and expected outcomes of the study were explained to each study subject. They were secured that all the gathered data will be used for the research purpose only, the study is harmless and their approval to participate is a prerequisite to be included in the study. Each subject was assured that they can withdraw whenever they want.

\section{Field Work}

-The data was collected from the identified subject by the researchers. The researchers met the staff nurses in small groups during their work shifts to distribute the questionnaire. The staff nurses recorded the answer in the presence of the researchers to ascertain all questions were answered and giving clarification.

- The suitable time for data collection varied according to the type of work and work load for each intensive care unit; sometimes it was done in the middle of the shift in other times before the end of the shift. The time needed to complete each questionnaire items from staff nurses were between 10-20 minutes.

-The data were collected over period of three months started from November 2019 to January 2020.

\section{Statistical Analysis}

Data entry and analysis were completed using statistical package for social science 
(SPSS) version 18. Data were presented using: Descriptive statistics in the form (frequency, percentage, mean and standard deviation, and Chi-square). Test of significant was prepared. Significant level value was measured when $\mathrm{p} \leq 0.05$ and $\mathrm{a}$ highly significant level value was measured when $\mathrm{p} \leq 0.01$.

\section{Results}

Table (1): Represents staff nurses distribution according to personal characteristics. It was observed that high percent $(83.11 \%)$ of staff nurses' age ranged from 21- 30 years. The majority staff nurses $(89.40 \%)$ were female nurses and $84.77 \%$ were married. Regarding working unit, $26.82 \%, 19.54 \%$, and $18.87 \%$ working in Neurological, Neonatal and Psychiatric intensive care units respectively. More than half $(53.97 \%)$ of staff nurses had 5-10 years of experience. Regarding academic qualification, high percent $(67.55 \%)$ had Bachelor degree while only $32.45 \%$ of them had nursing Diploma.

Table (2):Shows distribution of staff nurses' mean scores and stander deviation related to team effectiveness dimensions. As observed in the table, staff nurses' total mean scores and stander deviation related to total team effectiveness was 179.384 \pm 34.906 . The highest mean score $23.553 \pm 4.292$ was related to skills and learning dimension and the lowest mean score $21.195 \pm 4.938$ was related to team processes dimension.

Table (3):Illustrates distribution of staff nurses' mean scores and stander deviation related to organizational commitment dimensions. It was noticed that staff nurses' mean scores and stander deviation related to total organizational commitment was $30.530 \pm 4.858$. The highest mean score $11.053 \pm 2.109$ was related to continuance commitment dimension.

Table (4): Shows level of staff nurses' team effectiveness. It was observed that, slightly less than half $45.36 \%$ of staff nurses have moderate level of total team effectiveness. Also, about half $50.66 \%$ and $49.01 \%$ of staff nurses have moderate level of team effectiveness regarding intergroup relations and roles dimensions respectively. Equal percent $45.03 \%$ and $45.36 \%$ have moderate level of team effectiveness regarding passion and commitment and team process dimensions respectively

Table (5):Demonstrates relation between total team effectiveness and staff nurses' personal characteristics. As observed in the table, there is highly positive significant correlation between total staff nurses team effectiveness and their personal characteristics regarding years of 
experience, marital status and academic qualification at $\mathrm{p}<0.001$.

Table (6): Shows relation between total organizational commitment and staff nurses' personal characteristics. It was discerned that there are positive significant correlations between total organizational commitment and nurses' age, marital status and years of experience at $\mathrm{p}<0.001$.

Figure (1):Represents level of staff nurses' organizational commitment. It was noticed that, more than half $62.58 \%$ of staff nurses had moderate level of organizational commitment.

Figure (2):Illustrates level of organizational commitment dimensions. It was detected that, More than half 55.63\%, $53.31 \%$ and $49.34 \%$ of staff nurses had moderate level regarding continuance, normative and affective commitment respectively.

Figure (3):Represents relation between staff nurses total team effectiveness and their total organizational commitment. As observed, there is positive significant correlation between staff nurses total team effectiveness and their total organizational commitment at $\mathrm{p}<0.001$. 
Table (1): Staff nurses distribution according to personal characteristics $(n=302)$

\begin{tabular}{|c|c|c|c|}
\hline \multicolumn{2}{|c|}{ personal characteristics } & No. & $\%$ \\
\hline \multirow{4}{*}{ Age group } & 21-30 Years & 251 & 83.11 \\
\hline & 31-45 Years & 51 & 16.89 \\
\hline & Range & \multicolumn{2}{|c|}{$21-45$} \\
\hline & Mean \pm SD & \multicolumn{2}{|c|}{$28.384 \pm 4.855$} \\
\hline \multirow{2}{*}{ Gender } & Male & 32 & 10.60 \\
\hline & Female & 270 & 89.40 \\
\hline \multirow{2}{*}{ Marital status } & Single & 46 & 15.23 \\
\hline & Married & 256 & 84.77 \\
\hline \multirow{6}{*}{ Unit } & Neuro & 81 & 26.82 \\
\hline & Psy & 57 & 18.87 \\
\hline & Cardiology & 42 & 13.91 \\
\hline & Chest & 30 & 9.93 \\
\hline & Neonatal & 59 & 19.54 \\
\hline & Medical & 33 & 10.93 \\
\hline \multirow{5}{*}{ Years of Experience } & $<5$ Years & 104 & 34.44 \\
\hline & 5-10 Years & 163 & 53.97 \\
\hline & $>10$ Years & 35 & 11.59 \\
\hline & Range & \multicolumn{2}{|c|}{$1-25$} \\
\hline & Mean \pm SD & \multicolumn{2}{|c|}{$6.671 \pm 4.844$} \\
\hline \multirow{2}{*}{$\begin{array}{c}\text { Academic } \\
\text { Qualification }\end{array}$} & Bachelor of Nursing & 204 & 67.55 \\
\hline & Nursing Diploma & 98 & 32.45 \\
\hline
\end{tabular}

Table (2): Distribution of staff nurses' mean scores and stander deviation related to team effectiveness dimensions

\begin{tabular}{||l|rrr|rrr||}
\hline \multicolumn{7}{|c|}{ Descriptive Statistics } \\
\hline & \multicolumn{2}{|c|}{ Range } & Mean & \pm & SD \\
\hline Purpose and goals & 14 & - & 35 & 22.702 & \pm & 4.624 \\
\hline Roles & 12 & - & 35 & 22.556 & \pm & 4.565 \\
\hline Team processes & 11 & - & 35 & 21.195 & \pm & 4.938 \\
\hline Team relationships & 13 & - & 35 & 22.553 & \pm & 4.677 \\
\hline Intergroup relations & 11 & - & 35 & 22.407 & \pm & 4.529 \\
\hline Problem solving & 12 & - & 35 & 21.841 & \pm & 4.902 \\
\hline Passion and commitment & 13 & - & 35 & 22.576 & \pm & 4.824 \\
\hline Skills and learning & 13 & - & 35 & 23.553 & \pm & 4.292 \\
\hline Total Team Effectiveness & 103 & - & 280 & 179.384 & \pm & 34.906 \\
\hline
\end{tabular}


Table (3): Distribution of staff nurses' mean scores and stander deviation related to organizational commitment dimensions

\begin{tabular}{|l|rrr|rrr|}
\hline \multicolumn{7}{|c|}{ Descriptive Statistics } \\
\hline & \multicolumn{2}{|c|}{ Range } & Mean & \pm & SD \\
\hline Continuance Commitment & 5 & - & 15 & 11.053 & \pm & 2.109 \\
\hline Affective Commitment & 3 & - & 15 & 9.560 & \pm & 2.278 \\
\hline Normative Commitment & 3 & - & 15 & 9.917 & \pm & 2.068 \\
\hline Total organizational commitment & 12 & - & 45 & 30.530 & \pm & 4.858 \\
\hline \hline
\end{tabular}

Table (4): Level of staff nurses' team effectiveness dimensions

\begin{tabular}{|l|c|c|c|c|c|c|c|c||}
\hline \multirow{2}{*}{ Dimensions of team effectiveness } & \multicolumn{2}{|c|}{ Low } & \multicolumn{2}{c|}{ Moderate } & \multicolumn{2}{c|}{ High } & \multicolumn{2}{c|}{ Chi-Square } \\
\cline { 2 - 9 } & $\mathrm{N}$ & $\%$ & $\mathrm{~N}$ & $\%$ & $\mathrm{~N}$ & $\%$ & $\mathbf{X}^{\mathbf{2}}$ & P-value \\
\hline Purpose and goals & 107 & 35.43 & 131 & 43.38 & 64 & 21.19 & 22.894 & $<0.001^{*}$ \\
\hline Roles & 97 & 32.12 & 148 & 49.01 & 57 & 18.87 & 41.331 & $<0.001^{*}$ \\
\hline Team processes & 131 & 43.38 & 137 & 45.36 & 34 & 11.26 & 66.404 & $<0.001^{*}$ \\
\hline Team relationships & 105 & 34.77 & 124 & 41.06 & 73 & 24.17 & 13.199 & $0.001^{*}$ \\
\hline Intergroup relations & 100 & 33.11 & 153 & 50.66 & 49 & 16.23 & 53.728 & $<0.001^{*}$ \\
\hline Problem solving & 121 & 40.07 & 128 & 42.38 & 53 & 17.55 & 34.099 & $<0.001^{*}$ \\
\hline Passion and commitment & 102 & 33.77 & 136 & 45.03 & 64 & 21.19 & 25.775 & $<0.001^{*}$ \\
\hline Skills and learning & 74 & 24.50 & 139 & 46.03 & 89 & 29.47 & 23.013 & $<0.001^{*}$ \\
\hline Total Team Effectiveness & 112 & 37.09 & 137 & 45.36 & 53 & 17.55 & 36.960 & $<0.001^{*}$ \\
\hline
\end{tabular}

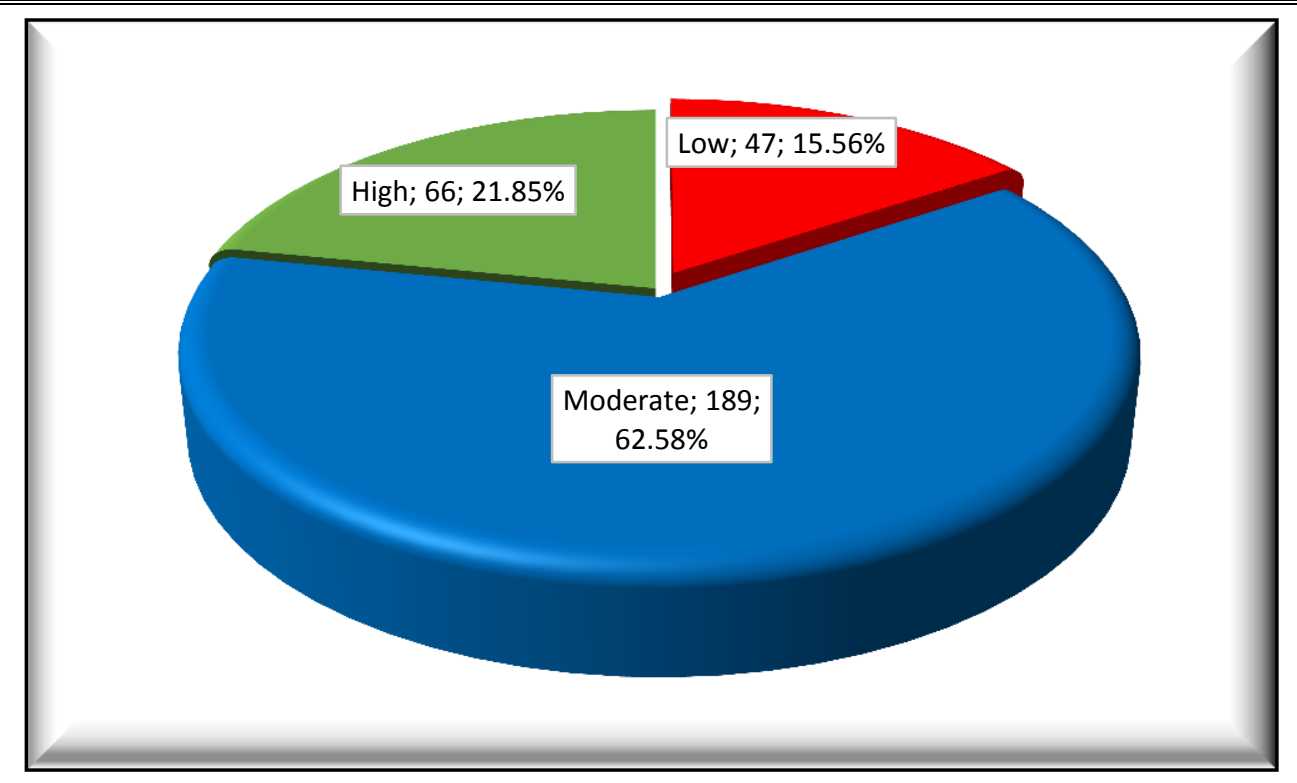

Figure (1): level ofstaff nurses' organizational commitment 


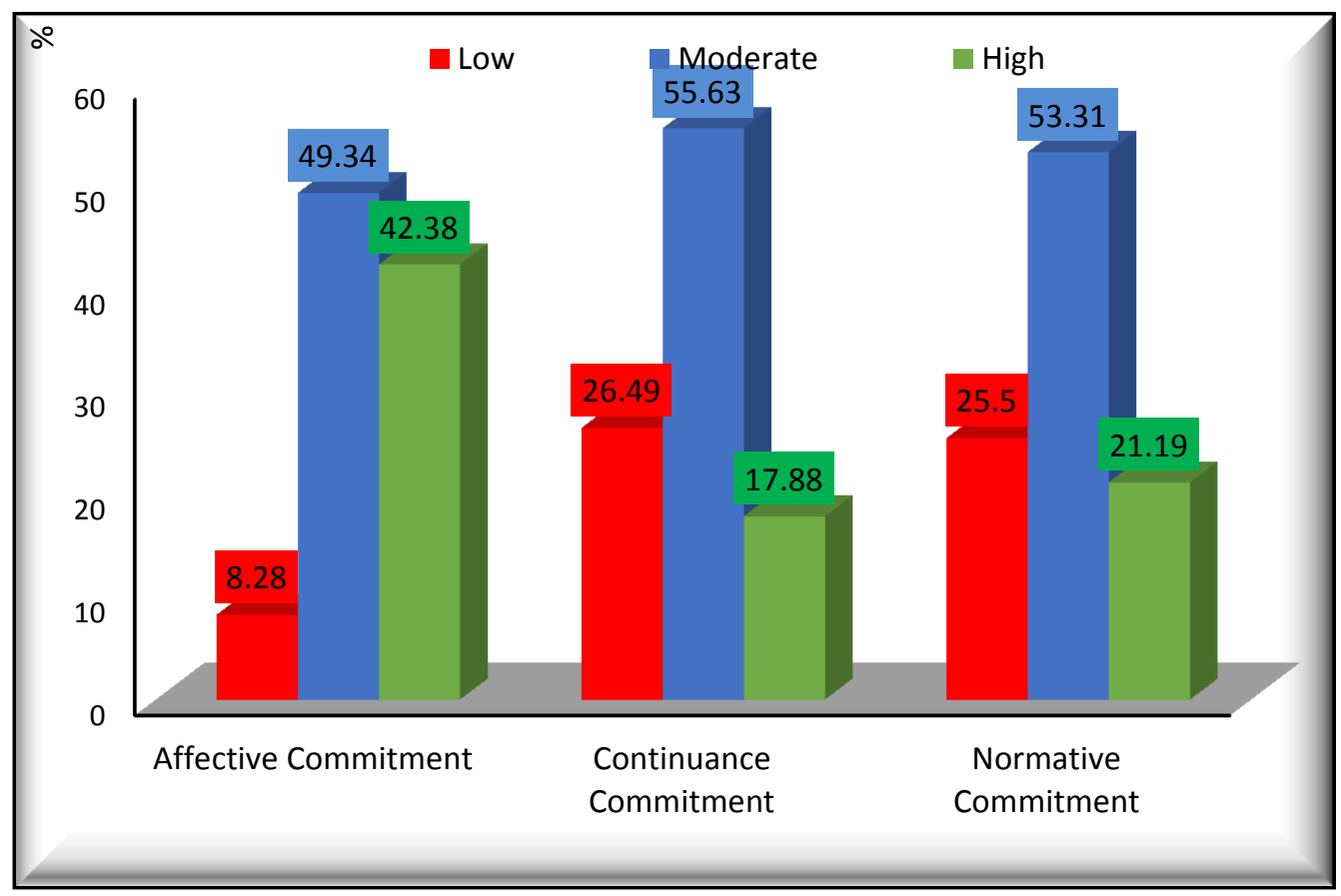

Figure (2): Level oforganizational commitmentdimensions.

Table (5): Relation between total team effectiveness and staff nurses' personal characteristics.

\begin{tabular}{|c|c|c|c|c|c|c|}
\hline & \multicolumn{3}{|c|}{ Total Team Effectiveness } & \multicolumn{2}{|c|}{ T-Test or ANOVA } \\
\hline & & $\mathbf{N}$ & Mean & SD & T or $\mathbf{F}$ & P-value \\
\hline \multirow{2}{*}{ Age group } & 21-30 Years & 251 & $178.566=$ & $\pm \mathbf{3 4 . 8 3 8}$ & \multirow{2}{*}{-0.904} & \multirow{2}{*}{0.367} \\
\hline & 31-45 Years & 51 & 183.412: & $\pm \mathbf{3 5 . 3 0 3}$ & & \\
\hline \multirow{2}{*}{ Gender } & Male & 32 & 176.500 & \pm 41.901 & \multirow{2}{*}{-0.494} & \multirow{2}{*}{0.622} \\
\hline & Female & 270 & $179.726=$ & $\pm \mathbf{3 4 . 0 5 7}$ & & \\
\hline \multirow{2}{*}{ Marital status } & Single & 46 & 162.348 & \pm 41.748 & \multirow{2}{*}{3.669} & \multirow{2}{*}{$<0.001 *$} \\
\hline & Married & 256 & $182.445=$ & $\pm \quad 32.694$ & & \\
\hline \multirow{6}{*}{ Unit } & Neuro & 81 & $183.926=$ & $\pm \quad 34.778$ & \multirow{6}{*}{1.863} & \multirow{6}{*}{0.101} \\
\hline & Phy & 57 & 173.316 & $\pm \quad 36.234$ & & \\
\hline & Cardiology & 42 & 190.643 : & $\pm \mathbf{3 3 . 6 3 1}$ & & \\
\hline & Chest & 30 & 176.200 : & $\pm \quad 21.804$ & & \\
\hline & Neonatal & 59 & 174.441: & $\pm \quad 37.705$ & & \\
\hline & Medical & 33 & 176.121 & $\pm \quad 36.507$ & & \\
\hline \multirow{3}{*}{$\begin{array}{c}\text { Years of } \\
\text { Experience }\end{array}$} & $<5$ Years & 104 & 183.452 : & \pm 34.639 & \multirow{3}{*}{10.381} & \multirow{3}{*}{$<0.001 *$} \\
\hline & 5-10 Years & 163 & 172.454: & $\pm \quad 34.984$ & & \\
\hline & $>10$ Years & 35 & 199.571: & $\pm \quad 24.897$ & & \\
\hline \multirow{2}{*}{$\begin{array}{c}\text { Academic } \\
\text { Qualification }\end{array}$} & Bachelor of Nursing & 204 & $\mathbf{1 7 4 . 7 9 4}$ & $\pm \quad 35.854$ & \multirow{2}{*}{-3.353} & \multirow{2}{*}{$0.001 *$} \\
\hline & Nurse Diploma & 98 & 188.939 & $\pm \mathbf{3 0 . 8 8 7}$ & & \\
\hline
\end{tabular}


Table (6): Relation between total organizational commitment and staff nurses' personal characteristics.

\begin{tabular}{|c|c|c|c|c|c|c|c|}
\hline & & \multicolumn{4}{|c|}{$\begin{array}{c}\text { Total Professional } \\
\text { commitment }\end{array}$} & \multicolumn{2}{|c|}{ T-Test or ANOVA } \\
\hline & & $\mathbf{N}$ & Mean & \pm & SD & T or $\mathbf{F}$ & P-value \\
\hline \multirow{2}{*}{ Age group } & 21-30 Years & 251 & 30.084 & \pm & 4.780 & \multirow{2}{*}{3.611} & \multirow{2}{*}{$<0.001 *$} \\
\hline & 31-45 Years & 51 & 32.725 & \pm & 4.682 & & \\
\hline \multirow{2}{*}{ Gender } & Male & 32 & 30.688 & \pm & 5.596 & \multirow{2}{*}{0.194} & \multirow{2}{*}{0.846} \\
\hline & Female & 270 & 30.511 & \pm & 4.774 & & \\
\hline \multirow{2}{*}{ Marital status } & Single & 46 & 28.761 & \pm & 7.288 & \multirow{2}{*}{2.711} & \multirow{2}{*}{$0.007 *$} \\
\hline & Married & 256 & 30.848 & \pm & 4.221 & & \\
\hline \multirow{6}{*}{ Unit } & Neuro & 81 & 29.963 & \pm & 5.038 & \multirow{6}{*}{1.272} & \multirow{6}{*}{0.276} \\
\hline & Phy & 57 & 31.737 & \pm & 5.446 & & \\
\hline & Cardiology & 42 & 31.071 & \pm & 2.797 & & \\
\hline & Chest & 30 & 30.400 & \pm & 3.024 & & \\
\hline & Neonatal & 59 & 29.847 & \pm & 6.147 & & \\
\hline & Medical & 33 & 30.485 & \pm & 3.890 & & \\
\hline \multirow{3}{*}{$\begin{array}{c}\text { Years of } \\
\text { Experience }\end{array}$} & $<5$ Years & 104 & 29.962 & \pm & 4.256 & \multirow{3}{*}{7.485} & \multirow{3}{*}{$0.001 *$} \\
\hline & 5-10 Years & 163 & 30.270 & \pm & 5.074 & & \\
\hline & $>10$ Years & 35 & 33.429 & \pm & 4.629 & & \\
\hline \multirow{2}{*}{$\begin{array}{c}\text { Academic } \\
\text { Qualification }\end{array}$} & Bachelor of Nursing & 204 & 30.902 & \pm & 4.745 & \multirow{2}{*}{1.930} & \multirow{2}{*}{0.055} \\
\hline & Nurse Diploma & 98 & 29.755 & \pm & 5.022 & & \\
\hline
\end{tabular}

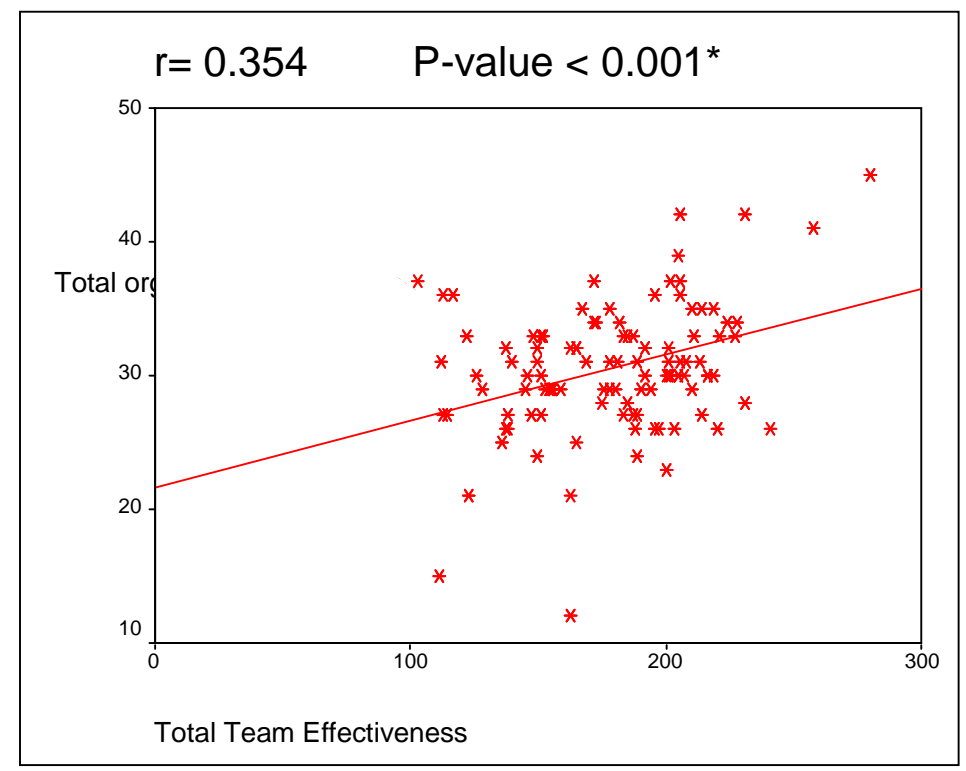

Figure (3): Relation between staff nurses total team effectiveness and their total organizational commitment. 


\section{Discussion}

Nursing teamwork effectiveness is a vital aspect of the functioning of any hospital and a basic structural component of hospitals' design especially in ICU. Ineffective ICU nursing teams can make it impossible for a hospital to work and develop, therefore it is necessary to know the level of ICU nursing team effectiveness ${ }^{(4)}$.Today's the health sector, should provide additional weight to nursing teamwork effectiveness particularly ICU nursing teams. Moreover, management can arrange activities for enhancing nurse's organizational commitment to increase their performance. Effective nursing teamwork can be predicted as one of the effectively adopted of the health services and the application of that is used to improve the nurses' organizational commitment ${ }^{(2)}$.

Result of present study revealed thatslightly less than half of staff nurses have moderate level of total nursing work team effectiveness.Factually, about half of staff nurses have moderate level of all team effectiveness dimensions including; purpose and goals, roles, team processes, team relationships, intergroup relations, problem solving, commitment and skills and learning dimensions. As well as little percent of nurses represent high level of nursing team work effectiveness.
These finding may be due to difficult to achieve effective team in ICU nursing practice because of the barriers between inter professional nursing groupings.Other factors which impede the creation of effective teams may include multiple lines of management, perceived status differentials between professional nursing groups, and lack of hospital systems and structures for supporting and managing effective teams. It is difficult to achieve effective level of teamwork may be due to large team size, lack of familiarity, instability of the work force and assignments, the absence of a common purpose and destiny, critical condition of ICU patients and an inhibiting physical environment.

Effective ICU nursing teamwork is essential and required for effective patient management, and an essential part of healthcare's organizational fabric for delivering quality care. The Affordable Care Act gives further impetus to the growing importance of teams in the healthcare arena. In fact, effective nursing teams generally provide better healthcare than individuals performing alone and need training to learn how to work together and to understand their roles and responsibilities ${ }^{(24,25)}$. 
Many researchers as BoveeandThill (2013) $^{(26)}$, Coole (2009) $)^{(27)}$ and Hakanen(2015) ${ }^{(28)}$ determined the ideal dimensions of effective team members including; clear sense of shared purpose, open and honest communication, focus and decision by consensus, a clearly defined vision, mutual trust and respect, clear roles and responsibilities, alsoCheruvelil et al. $\mathbf{( 2 0 1 4}^{(29)}$ noted that team diversity and interpersonal skills and clear and specific purpose are three of the most important components in the building and maintaining of effective team, as well as he revealed that the members of effective teams have the necessary skills and knowledge and they share the same understanding of the vision and goals. The members of effective teams share responsibility for and commitment to the main purpose. Clear standards and functioning decision-making and problem solving were also seen as important factors for the effective team.

\section{Andreatta (2010) ${ }^{(\mathbf{3 0})}$, Westet}

al. ${ }^{(31)}$ Support the present study and suggest that, although over ninety percent of staff report that they work in a team, only just over half of these staff report that their team effective. Beatrice and Rochman $(\mathbf{2 0 1 8})^{(\mathbf{3 2})}$ not support present study and demonstrate that nursing teams on acute care patient units have a higher level of teamwork.Bakeret al. (2010) ${ }^{(\mathbf{3 3})}$ found improvements in team working processes specifically in relation to better communication and greater intra-team respect.

Result of current study showed that, more than half percent of staff nurses had moderate level of total organizational commitment. Statistically more than half of ICU nursing staff had moderate level regarding continuance, normative and affective commitment. This finding may be due tonurses' role ambiguity, job insecurity, job dissatisfaction and lacked of organizational support. Not surprise thatthe highest mean score is related to continuance commitment this may be due to Egyptian nursing staff preferred governmental than private work and not looking for to any positions than their work in governmental hospital.As well as it would be very hard for them to leave their organization because of their life would be disrupted if they decided to leave their organization, and scarcity of available alternatives.

Our result is in line with many researchers asAlHaroon (2020) $^{(19)}$,Salemet al.(2016) ${ }^{(34)}$, Salehet al. (2014) ${ }^{(35)}$, and Arbabisarjouet al. (2016) ${ }^{(36)}$ theyrevealed that the nurses had a moderate overall organizational commitment level. As well as is consistent with the AlHaroon and 
Al-Qahtani(2020) $)^{(19)}$ and $\operatorname{Saleh}(2014)^{(35)}$ findings, which showed that nurses had a higher mean score for continuous commitment than affective and normative. It was wonder that the lowest mean score pertained to the affective commitment. Nurse managers should increase the nurses' affective commitment to increase their performances. $\operatorname{McElroy}(\mathbf{2 0 0 1})^{(37)}$ pointed out some suggestions to improve staff organizational commitment, including job security, optional payment, autonomous groups and decentralization, proper compensate by organizational performance and reduce position differences.

The present study revealed that there is positive significant correlation between nursing staff total team effectiveness and their personal characteristics regarding years of experience and academic qualification. As well as there are significant correlations between total professional commitment and nurses' personal characteristics regarding age and years of experience.

Mustafa (2016) ${ }^{(14)}$ support present finding and indicated that older employees had higher teamwork and organizational commitment scores than younger employees. It can be understood from this result that experienced employees pay importance to teamwork, so that; their commitment to the organization can be increased depending on the experience. Another approach shows that depending on experience, the sense of ownership of the job increases both the commitment and team spirit.

AlHaroon (2020) $)^{(19)}$ revealed that the youngest nurses were the least committed ones. Older nurses appeared to be more committed to the organization. This result might be clarified by the level of enthusiasm of older people, which is expected to be lower than that of younger nurses, who often hunt for new job perspectives and find it easy to switch jobs and transfer. Age and experience are highly related to organizational commitment; therefore organizational decision makers place more emphasis on retaining older nurses because they are more committed to their jobs than younger nurses.

Eleswed (2013) ${ }^{(38)}$ finding revealed that age was demographic factor that affected the level of organizational commitment, However, our results contradict the findings of Arbabisarjou (2016) ${ }^{(36)}$ which indicate that there are not significant relationships between organizational commitment and sociodemographic data, such as gender, educational level and working experience. 
The present study explored that there is positive significant correlation between ICU staff nurses total team effectiveness and total organizational commitment. The commitment of nurses is an important issue because it may be used to predict nurses' performance, absenteeism and other behaviors. Hospitals management staff that demonstrate commitment to nurses will attract and retain them and will ultimately win the battle for the nurses' share.

Edwardet al. (2016) $)^{(2)}$ stated that teamwork is essential for hospital enhancement. It enhancesnurses' commitment to an organization and their job satisfaction. His results show that team work and commitment correlate positively.Mustafa (2015) ${ }^{(14)}$ demonstrates that there is a positive significant linear correlations between teamwork and organizational commitment. Also Hosseini(2012) ${ }^{(39)}$ Finding showed that working team was positively related to the organizational commitment.

The ICU nurses with effective teamwork experiences are more likely tofeel bonded to their hospital and less inclined to want to separate from it. Nurses' perceptions of team effectiveness directly and positively impacted commitment to the hospital and had a range of effects on turnover intentions via satisfaction, commitment, and perceptions of work overload. Higher levels of perceived effective teams work directly increased perceptions of job satisfaction and organizational commitment $^{(14)}$.

\section{Conclusion}

Based on the findings of this study, it can be concluded that staff nurses had moderate level of work team effectiveness and also their organizational commitment. There is positive significant correlation between total staff nurses team effectiveness and total organizational commitment. There is also, positive significant correlation between staff nurses total team effectiveness and their personal characteristics regarding years of experience, marital status and academic qualification. It was discerned that there are positive significant correlations between total organizational commitment and nurses' age, marital status and years of experience

\section{Recommendation}

The current study recommends the following:

For hospital administration

- Adjust hospital policies to focus hospital systems and structures on team - based rather than hierarchal

- Creating continuous assessment and evaluation of team effectiveness to 
determine which dimensions of team effectiveness need to be improved

For head nurses

- Training nursing staff for working in teams.

- Allow staff nurses to participate in putting goal and purpose of their team that will incorporate to improve team relationship, intergroup relationships, compassion and commitment to their team and to the hospital as a whole.

- Clearly defined roles for each staff nurse in team composition to improve team effectiveness

- Empower staff nurses to participate in solving problems of their team to increase coherence between them and to the organization as a whole

- Pay attention to heterogeneity of skills between members of team to achieve effectiveness

- Emphasize the importance of team effectiveness and how to make team effective in continuing education and training programs.

- Further research: effect of nursing team effectiveness dimensions on job outcomes.

\section{References}

1- Nemanja B, Agnes S, Marko A. Relationship between perceived teamwork effectiveness and team performance in banking sector of
Serbia. Sustainability. 2020; 12. 8753:1-15.Doi:10.3390/su12208753

2- Edward S, Greenberg Patricia B, SikoraL, Grunberg S. Work teams and organizational commitment : Exploring the influence of the team experience on employee attitudes more workplace change project working Paper WP012.Available at: https://www.scribd.com/document/2201 94788/oc

3- Jee-In H, Jeonghoon A. Teamwork and clinical error reporting among nurses in Korean hospitals.Asian Nursing Research. 2015; 9(1):14e20.

4- Eduardo S, Marissa L, Shuffler M, Amanda L, Elizabeth H. Understanding and improving teamwork in organizations.A Scientifically Based Practical Guide, Human Resource Management Journal. 2014; 24(4):599-622.

5- Penelope F. The meaning of commitment in professional service relationships: Issues in relating theory to practice.2011Cranfield University. Available at: https://www.impgroup.org/uploads/pap ers/58.pdf

6- Ramón R, Carlos M, Carmen T. Work team effectiveness, a review of research from the last decade. Psychology in Spain Journal, 2011; 15 (1):57-79. 
7- Ervin J, Kahn J, Cohen T, Weingart L. Team work in the intensive care unit. American Psychologist Journal.2018; 73(4): 468-477.

8- Team Effectiveness Questionnaire. Available at: https://www.cu.edu/sites/default/files/T eam_effectiveness_questionnaire.

9- Mehta A, Mehta N. Knowledge integration and team effectiveness: A team goal orientation approach.Decision Sciences Institute Journal.2018; 49(3): 445-55.

10- Todd R, Logan D. Influence of teamwork behaviors on workplace incivility as it applies to nurses. Creighton Journal of Interdisciplinary Leadership. 2018; 2(1): 47 - 53.

11-Beatrice K, Suzanne M, Begeny S. Improving nursing unit teamwork. The Journal of Nursing Administration. 2005; 35(12):550-556. World Health Organization Being an effective team player.Available at:http://www.who.int/about/licensing/e n/index.html , 2012; 1-5

12- Martina S, Kirti D, DoekhieA, Jeroen D , Van W. Interventions to improve team effectiveness within health care: A systematic review of the past decade. Human Resources for Health Journal, 2020; 18(2): 1-3. Available at:https://doi.org/10.1186/s12960-019-

0411-3

13-Evert S, Lars T, Mirko N. Working on working together. A systematic review on how healthcare professionals contribute to interprofessional collaboration. Journal of Available at: https://www.tandfonline.com/loi/ijic20

14- Mustafa Z, Abdurrahim E, Mehmet Y. Analysis of teamwork, organizational commitment and organizational performance: A study of health sector in Turkey. Asian Journal of Business and Management. 2015; 3( 02):173-175

15-Lorber M, Skela-Savič B. Factors affecting nurses' organizational commitment.

ObzornikZdravstveneNege Journal. 2014; 48(4): 294- 301.

16-AzizollahA , Hamed S , Sadegh D, Hassan R. Organizational commitment in nurses .International Journal of Advanced Biotechnology and Research. 2016;7 (5): 1841-1846.

17-Mwangi G. Factors Influencing Commitment and Engagement of Healthcare Workers at Kkenyatta National Hospital. Published Master Dissertation of Business Administration .University of Nairobi, 2015; 20-25.

18-Hakami A, AlmutairiH , Al Otaibi R , Al Otaibi T, Al Battal A. Relationship between nurses' job satisfaction and 
organizational commitment. Health Science Journal. 2020; 14 (1): 692.

19- AlHaroon H, Al-Qahtani M. Assessment of organizational commitment among nurses in a major public hospital in Saudi Arabia. Journal of Multidisciplinary Healthcare. 2020;13: 519-526.

20- Rentala, S. Basics in Nursing Research and Biostatistics. $\quad 1^{\text {st }}$ Ed,London: JaypeeBrothers

Medical Publishers;2019. 130.

21-Boru T. Research Design and Methodology. Chapter Five. Available at

:https://www.researchgate.net/publicati on/329715052

22-Lurie, J, Schultz H, Lamanna, G. Assessing teamwork. Family Medicine Journal. 2011; 43(10): 731-734.

23-Meyer J,AllenJ. Commitment in the workplace. Thousand Oaks. 1997. CA: SAGE publication:

24- Hughes A, Gregory M, Joseph D, Sonesh S, Marlow S, Lacerenza C, et al. Saving lives: A meta-analysis of team training in healthcare. Journal of Applied Psychology, 2016; 101(1):1266-1304.

Doi:10.1037/apl0000120. [PubMed: 27599089]

25-Stephen H, Mary K, Stephen M. Organizational leadership for building effective health care teams.Annals of Family Medicine Journal. 2013;11(3): 279.

26- BoveeC,Thill J. Business

Communication Essentials.

$6^{\text {th }}$ Ed.Prentice Hall, 2013.

27-Coole S. Building a high performing team. Proven techniques for effective team working. Cambridgeshire: IT Governance Publishing; 2009.

28-Hakanen M, Soudunsaari A. Trust in building high-performing teams conceptual approach. Electronic Journal of Business Ethics and Organization Studies. 2015;20(2): 43-55.

29- Cheruvelil K, Soranno A, Weathers C, Hanson C, Goring J, FilstrupT, and et al. Creating and maintaining highperforming collaborative research teams: The importance of diversity and interpersonal skills. Frontiers in Ecology and the Environment. 2014; 12(1): 31-38.

30- AndreattaB. A typology for health care teams. Health Care Management Review. 2010; 35(4): 345-54.

31-West A, Alimo-Metcalfe B, Dawson F, El Ansari W, Glasby J, Hardy G, et al. Effectiveness of Multi-Professional Team Working (MPTW) in Mental Health Care. Final Report. NIHR Service Delivery and Organization Program; 2012. 
32- Beatrice J, RochmanR.Nursing staff teamwork and job satisfaction. Journal of Nursing Management. 2018; 18(1):938-47.

33- Baker D, and et al.Assessing teamwork attitudes in health care, development of the team. Quality and Safety in Health Care Journal. 2010; 19(6): 1-4.

34-. Salem O, Baddar F, AL-Mugatti H. Relationship between nurses' job satisfaction and organizational commitment. J.Nur. Health Sci. 2016;5(1):49-55

35-Saleh AM, Darawad MW, Al-Hussami M. Organizational commitment and work satisfaction among Jordanian nurses: A comparative study. Life Sci J. 2014;11(2):31-36.

36- Arbabisarjou A, Hamed S, Sadegh DM, Hassan R. Organizational commitment in nurses. Int. J. Adv. Biotechnol. Res. 2016;7 (5):1841-1846.

37-McELROY JC. Managing workplace commitment by putting people first. Human Resource Management Review. JAI. 2001; 11(3): 327-335.

38-. Eleswed M, Mohammed F. Job satisfaction and organizational commitment: A correlational study in Bahrain. Int. J. Bus.Humanit Technol. 2013; 3(5):44-53.

39- Hosseini M.Analysis of team working on organizational commitment in Safa
Industrial Group in Iran.International Journal of Engineering and Science.2012;1(3):22-25. 